\title{
Yunus ve Balina Bilgi Sistemi: Türkiye Denizleri Durum Çalışması
}

\section{Cetacean Information System: Case Study for Turkish Seas}

\section{Fethi Bengil $1^{*}$}

${ }^{1}$ Girne Amerikan Üniversitesi, Rektörlük Binası 2. Kat, Üniversite Yolu PK5., Karmi Kampus, Karaoğlanoğlu, Girne Kuzey Kıbris Türk Cumhuriyet, Mersin, TÜRKIYE

Sorumlu Yazar / Corresponding Author* fethibengil@gau.edu.tr

Geliş Tarihi / Received: 08.06.2018

DOI:10.21205/deufmd.2019216127

Kabul Tarihi / Accepted: 05.09.2018

Araștırma Makalesi/Research Article

Atıf șekli/How to cite: BENGIL, F.(2019). Yunus ve Balina Bilgi Sistemi: Türkiye Denizleri Durum Çalışması. DEUFMD, 21(61), 279-285

\section{$\ddot{0} \mathrm{z}$}

Yunus ve balina türlerini içeren setase grubu üyeleri besin ağındaki son tüketicilerden olması sebebiyle sürekli olarak insanoğlu ile bir rekabet içerisindedir. Bu rekabet bu türlerin yok olma tehlikesiyle karşı karşıya kalmasına neden olmaktadır. Bu çalışmada, Türkiye denizlerinde tespit edilmiș setase türlerinin dağılım bilgilerini üreten örnek bir bilgi sistemi geliștirilmiștir. Durum çalışması olarak 1986-2014 yılları arasında yayımlanmış literatür bilgisi ve 2012-2017 yılları arasında yazar tarafından toplanmıș rastlantısal gözlemleri içeren bir bilgi sistemi olușturulmuștur. Türkiye denizlerinde en yaygın gözlemlenen türün Tursiops truncatus olduğu belirlenmiștir. Bunun yanından tür çeşitliliğinin en fazla olduğu bölgelerin ise Ege ve Akdeniz kıyıları olduğu görülmüștür. Geliștirilen bilgi sistemi kullanılarak yapılan analizlerle türlere ait coğrafik dağılımı ve coğrafik bilgi boşluklarının tespitine yönelik bilgi ortaya konulmuştur. Bu sayede ulusal olarak korumaya yönelik bölgesel ve/veya türe yönelik yönetim planlarının belirlenmesine katkı sağlanmıștır. Tespit edilen türlerin küresel koruma statüleri ise böyle bir bilgi sisteminin gerekliliğini bir kez daha vurgulamaktadır.

Anahtar Kelimeler: Setase, Koruma, Coğrafi Bilgi Sistemi, Yönetim, Türkiye Denizleri

\begin{abstract}
Cetaceans are one of the top predators of the food web; in addtion to this, they always compete with humankind. They are mostly endangered or extinction species due to this challenge. This study aims to provide an example information system on present frequency and distributions of cetacean species based collecting literature data between 1986 and 2014 and some available sporadic observations (2012-2017) by author. Results showed that Tursiops truncatus is the most common species of the Turkish seas. Results also indicated the Aegean and the Levantine coasts have the highest diversity regarding to cetacean species. .The system produce information on distribution of each species as well as determine the information gaps throughout Turkish coasts. Thus, the products of the study contribute to implement management plans regarding to conservation of regions and/or the species. Additionally, conservation status of the species used in study also pointed out that such an information system is required for this group.
\end{abstract}

Keywords: Cetacea, Conservation, Geographic Informatio System, Management, Turkish Seas 
DEU FMD 21(61), 279-285, 2019

\section{Giriş}

Bugüne kadar yapılan çalışmalar neticesinde 21 setase ordosuna ait türün Akdeniz ve Karadeniz havzasında düzenli olarak belirli bir yoğunlukta varlığı tespit edilmiștir [1-2]. Bu türlerden 14 tanesinin ise doğu Akdeniz bölgesinde gözlemlendiği belirtilmiştir [3]. Bugüne kadar Türkiye denizlerinde ise 10 adet türün varlığı bildirilmiștir [4].

Bugüne kadar Türkiye kara suları bölgesinde yunus ve balina türleri üzerine çalıșmalar olmakla birlikte, bu çalışmalar kısıtlı bir coğrafik alan içerisinde [5] veya kıyıya vurma [6-7], hedef dışı yakalanmalar [8], balıkçılık etkileșimi [9] gibi bazı konular üzerinde odaklanmıșlardır. Bunun yanında rastlantısal gözlemler de rapor edilmiştir [10]. Türkiye kıyı uzunluğu dolayısı ile geniș deniz alanları göz önünde bulundurulduğunda, tüm kıyıları kapsayan bir çalıșma yapmak oldukça zordur. $\mathrm{Bu}$ durum, rastlantısal gözlemleri ve yapılan çalışmaları derleyecek bir bilgi sistemi ihtiyacını göz önüne getirmektedir. Geliștirilecek böyle bir bilgi sistemi, koruma öncelikli türleri içeren setase grubu için ulusal bir yönetim planı geliștirmeyi olanaklı hale getirmenin yanında, Türkiye deniz alanları içerisindeki bilgi boşluklarının değerlendirilmesini de olanaklı kılacaktır.

Bu çalışma kapsamında bugüne kadar Türkiye denizlerinde tespit edilmiș setase türlerinin dağılım bilgilerini üreten örnek bir bilgi sistemi geliștirilerek, bu türlerin ulusal düzeyde korunmalarına yönelik politikaların geliştirilmesine katkı sağlanması amaçlanmıștır. Durum çalışması olarak 19862014 yılları arasında yayımlanmıș literatür bilgisi ve 2012-2017 yılları arasında yazar tarafından toplanmış rastlantısal gözlemleri içeren bir bilgi sistemi olușturulmuș ve türlere ait dağılım haritaları olarak sunulmuștur. İkinci bir amaç, geliștirilmiş bu bilgi sistemi yardımı ile bilgi boşluklarının yersel dağılımı ortaya konularak, gerçekleștirilecek yeni çalışmaların ulusal düzeyde bilgi eksikliklerinin doldurulmasına yönelik tasarlanmasını olanaklı kılmaktır.

\section{Materyal ve Metot}

Setase türlerinin yersel dağılımlarını sunmak amaciyla, Türkiye'yi çevreleyen deniz bölgeleri çalışma alanı olarak belirlenmiștir. Türkiye 8333 km kıyı uzunluğuna sahip olmakla birlikte farklı özelliklere sahip; Karadeniz, Marmara Denizi ve doğu Akdeniz'in iki önemli parçası olan Ege ve Levant Denizi ile çevrelenmiștir.

Türkiye denizlerine ait yunus ve balina türlerini yersel dağılımlarını sunacak bir bilgi sistemi oluşturmak adına, 1986 yılından 2015 yılına kadar yapılmış canlı yunus ve balina türlerine ait kayıtları içeren yayınlar (süreli bilimsel yayınlar, süreli popüler yayınlar ve tezler [8-19]) taranarak veri sistemine giriși yapılmıştır. Veri setinin oluşturulmasına kullanılan yayınlar kaynaklar listesinde belirtilmiștir. Bahsi geçen bu yayınların yanında, yazar tarafından gözlemlenmiş ya da fotoğraf ile teyit edilmiș, 2012-2017 yılları arasında İzmir Körfezi çoğunluklu olarak Ege, Marmara ve Levant Denizi kıyılarına ait rastlantısal gözlemler de (Tablo 1) veri sistemine ișlenmiștir. Bilgi sistemine yayınlardan elde edilmesi mümkün olan en fazla veri aktarılmıștır. Genel olarak sistem yayın ismi, gözlem yeri, gözlem koordinatları, gözlem zamanı, gözlem yöntemi, gözlenen tür adı ve gözlenen birey sayısı gibi veri alanlarında veri girișini içermektedir. Sisteme veri girişinin tamamlanması ile birlikte, elde edilen veri sistemi, bilgi üretmek amacı ile coğrafi bilgi sistemine (CBS) aktarılmıștır. Veri sistemine ait veri ile yapılabilecek her türlü bilgi üretmeye yönelik ișlem ızgara sistemi üzerinde yapılması planlanmıștır. Türkiye deniz alanları yarım derecelik ızgaralara bölünerek, tür dağılım bilgi tabakası ile ızgara tabakası çakıștırılmıștır. Coğrafi olarak gruplandırılmıș gözlem bilgisi bu șekilde ızgara tabakası üzerinde sunulmuștur. Bu sistem ayrıca gözlemlenen toplam birey sayısı, toplam gözlem sayısı gibi bilgiler de üretilmeye uygun hale getirilmekle birlikte, yapılan çalıșmaların sistemli olmaması ve kullanılan yöntemlerin birbiri ile ilişkilendirilememesinden dolayı bilgi üretmekte bazı sınırlamalar söz konusu olmuştur.

\section{Bulgular}

Toplamda 681 yunus ve balina türlerine ait kayıt elde edilmiştir. $\mathrm{Bu}$ gözlemler kapsaminda 8 türe ait, Phocoena phocoena, Tursiops truncatus, Delphinus delphis, Stenella coruleoalba, Gramphus griseus, Mesoplodon sp., Pseudoorca crassidens and Physeter catadon, dağılım bilgileri elde edilmiştir (Tablo 2). 
DEU FMD 21(61), 279-285, 2019

Gözlemlerin büyük bir çoğunluğu İstanbul ve Çanakkale boğazlarını da kapsayacak şekilde Marmara denizinden gelmiștir $(\% 83,85)$. Türe yönelik değerlendirmede ise T. truncatus en fazla gözlenen tür olduğu tespit edilmiştir $(\% 44,35)$. Diğer sık gözlenen iki tür ise $D$. delphis $(\% 25,55)$ ve $P$. phocoena $(\% 24,38)$ olarak tespit edilmiștir (Tablo 2). Denizlere göre tespit edilen türler Tablo 3'de gösterilmiștir.

Gözlenen birey sayıları 1 ile 130 arasında dağılmaktadır. En yüksek birey sayısı 130 ile $D$. delphis ve 100 birey ile $P$. phocoena türlerinde gerçekleșmiștir. Gözlem bașına ortalama birey sayılar hesaplandığında en fazla ortalama sayının Karadeniz kayıtlarına ait olduğu görülmüștür (51 birey/gözlem). Bu sayı Marmara denizi için 10, Ege denizi için 3 ve Levant denizi için 6 olarak tespit edilmiștir. Her bir ızgara alanı için hesaplanan ortalama gözlem başına birey sayısı Şekil 1'de sunulmuştur.

Gözlenen birey sayıları 1 ile 130 arasında dağılmaktadır. En yüksek birey sayısı 130 ile $D$. delphis ve 100 birey ile $P$. phocoena türlerinde gerçekleșmiștir. Gözlem bașına ortalama birey sayılar hesaplandığında en fazla ortalama sayının Karadeniz kayıtlarına ait olduğu görülmüștür (51 birey/gözlem). Bu sayı Marmara denizi için 10, Ege denizi için 3 ve Levant denizi için 6 olarak tespit edilmiştir. Her bir ızgara alanı için hesaplanan ortalama gözlem başına birey sayısı Şekil 1'de sunulmuștur

Tablo 1. 2012-2017 yılları arasında teyit edilmiș yunus gözlemleri

\begin{tabular}{|c|c|c|c|c|}
\hline No & Yll & Enlem ( $\left.{ }^{\circ}\right)$ & Boylam ( ${ }^{\circ}$ ) & Tür \\
\hline 1 & 2012 & 41.017 & 29.003 & Tursiops truncatus \\
\hline 2 & 2012 & 40.996 & 28.969 & Tursiops truncatus \\
\hline 3 & 2012 & 39.477 & 26.598 & Tursiops truncatus \\
\hline 4 & 2012 & 40.043 & 26.334 & Tursiops truncatus \\
\hline 5 & 2012 & 38.4247 & 26.424 & Tursiops truncatus \\
\hline 6 & 2012 & 38.662 & 26.717 & Tursiops truncatus \\
\hline 7 & 2012 & 38.712 & 26.722 & Tursiops truncatus \\
\hline 8 & 2012 & 38.699 & 26.718 & Tursiops truncatus \\
\hline 9 & 2012 & 38.669 & 26.72 & Tursiops truncatus \\
\hline 10 & 2012 & 38.419 & 27.116 & Tursiops truncatus \\
\hline 11 & 2012 & 38.68 & 26.52 & Delphinus delphis \\
\hline 12 & 2012 & 39.94 & 26.147 & Delphinus delphis \\
\hline 13 & 2012 & 41.113 & 29.074 & Delphinus delphis \\
\hline 14 & 2013 & 38.415 & 26.388 & Tursiops truncatus \\
\hline 15 & 2013 & 38.445 & 27.117 & Tursiops truncatus \\
\hline 16 & 2013 & 38.668 & 26.586 & Delphinus delphis \\
\hline 17 & 2013 & 38.651 & 26.717 & Delphinus delphis \\
\hline 18 & 2014 & 38.415 & 26.421 & Tursiops truncatus \\
\hline 19 & 2014 & 38.514 & 26.373 & Tursiops truncatus \\
\hline 20 & 2016 & 41.471 & 31.723 & Tursiops truncatus \\
\hline 21 & 2016 & 36.529 & 35.638 & Tursiops truncatus \\
\hline 22 & 2016 & 36.105 & 35.539 & Tursiops truncatus \\
\hline 23 & 2016 & 38.506 & 26.638 & Tursiops truncatus \\
\hline 24 & 2016 & 38.525 & 26.364 & Delphinus delphis \\
\hline 25 & 2016 & 38.366 & 26.203 & Delphinus delphis \\
\hline 26 & 2017 & 41.017 & 37.974 & Tursiops truncatus \\
\hline 27 & 2017 & 38.655 & 26.52 & Tursiops truncatus \\
\hline
\end{tabular}


DEU FMD 21(61), 279-285, 2019

Tablo 2. Gözlemlerin türlere ve denizlere göre yüzde (\%) dağılımı.

\begin{tabular}{lccccc}
\hline & Levant Denizi & Ege Denizi & Karadeniz & Marmara Denizi & Toplam \\
\hline D. delphis & $0,15 \%$ & $1,62 \%$ & $0,00 \%$ & $23,79 \%$ & $25,55 \%$ \\
G. griseus & $0,15 \%$ & $0,44 \%$ & $0,00 \%$ & $0,00 \%$ & $0,59 \%$ \\
M. bidens & $0,00 \%$ & $0,15 \%$ & $0,00 \%$ & $0,00 \%$ & $0,15 \%$ \\
P. phocoena & $0,00 \%$ & $0,00 \%$ & $0,15 \%$ & $24,23 \%$ & $24,38 \%$ \\
P. catadon & $0,15 \%$ & $0,73 \%$ & $0,00 \%$ & $0,00 \%$ & $0,88 \%$ \\
P. crassidens & $0,00 \%$ & $0,15 \%$ & $0,00 \%$ & $0,00 \%$ & $0,15 \%$ \\
S. coeruleoalba & $0,73 \%$ & $3,23 \%$ & $0,00 \%$ & $0,00 \%$ & $3,96 \%$ \\
T. truncatus & $1,32 \%$ & $7,05 \%$ & $0,15 \%$ & $35,83 \%$ & $44,35 \%$ \\
\hline \multicolumn{1}{c}{ Toplam } & $\mathbf{2 , 5 0 \%}$ & $\mathbf{1 3 , 3 6 \%}$ & $\mathbf{0 , 2 9 \%}$ & $\mathbf{8 3 , 8 5 \%}$ & $\mathbf{1 0 0 , 0 0 \%}$ \\
\hline
\end{tabular}

Tablo 3. Gözlemlenen türlerin Türkiye denizlerinde dağılımları.

\begin{tabular}{lcccc}
\hline & Levant Denizi & Ege Denizi & Karadeniz & Marmara Denizi \\
\hline D. delphis & + & + & & + \\
G. griseus & + & + & + & + \\
M. bidens & & + & \\
P. phocoena & + & + & \\
P. catadon & & + & + \\
P. crassidens & + & + & + \\
S. coeruleoalba & + & + & + \\
T. truncatus & & + & \\
\hline
\end{tabular}

\section{Tartışma ve Sonuç}

Çalışma kapsamında olușturulan bilgi sistemi temelinde yapılan analizler, Türkiye'de yunus ve balına türleri üzerine yeter sayıda çalışma olmasına rağmen, bu bilginin sınırlı bölgelerde toparlandığını işaret etmektedir. İstanbul boğazı ve İzmir Körfezi gibi araştırmaların yoğun olduğu bölgeler de yönetime yönelik bilgi üretmenin mümkün olduğu, bunun dışında kalan bölgeler için hala gerekli bilgi üretmeye yönelik veri ihtiyacının gerekli olduğu görülmektedir. $\mathrm{Bu}$ çalışmanın sonuçları ileride gerçekleştirilecek bilgi ihtiyacına yönelik çalışmaların şekillendirilmesinde önemli bir katkı sağlayacaktır. Sonuçlar özellikle Levant Denizi ve Karadeniz kıyılarında setase türlerini araştırmaya ve kayıtlamaya yönelik özel bir çaba gerekliliğini vurgulamaktadır. Ölü bireylerin fiziksel etkenlerden dolayı gerçek dağılım bölgeleri dışında bulunma durumları göz önünde bulundurularak bu çalıșmanın kapsamına rapor edilmiş ölü karaya vuran bireylere ait çalışmalar dahil edilmemiștir. Bu kapsam dahilinde bulgular Türkiye'yi çevreleyen denizlerde ait veri açığını daha çarpıcı şekilde göz önüne koymaktadır.

Karadeniz'de az gözlem sayısı olmasına rağmen en yüksek birey gözlemleri gerçekleștirilmiştir. $\mathrm{Bu}$ durum denizler arasındaki gözlemlenen ortalama birey sayılarının bu denli farklı olmasını açıklamaktadır. Ayrıca, Karadeniz'de yaşayan P. phocoena türünün kalabalık gruplar halinde yaşaması da bu farklılığı tür davranışlarına bağlı olarak açıklamaktadır [20].

Bilgi sisteminden üretilen sonuçlar ışığında, Türkiye'nin Ege ve Doğu Akdeniz (Levant Denizi) kıyıları tür çeşitliliği bakımından en zengin bölgeler olarak tespit edilmiştir. Söz gelimi, İstanbul boğazı en fazla gözlemi içeren ızgaraya sahip olmakla birlikte yalnızca 3 türün varlığını işaret etmektedir. Levant Denizi'nde yapılacak sistemli çalışmalar Türkiye denizlerindeki yunus ve balina faunasının tam olarak belirlenmesi konusunda avantaj sağlayacaktır.

Mesopolodon genusu Akdeniz'in tamamı için yaygın bir grup değildir [21-22]. Doğal dağılımından çok uzak olmasına rağmen, 2009 yılında Fethiye limanında bir canlı karaya vuran Mesoplodon sp. bireyi gözlemlenmiş ve tekrar doğaya döndürülmüştür. Bu gözlem, bölgenin gerek topografisinden gerek ise Rodos döngüsü gibi akıntı özelliklerinden dolayı, Ege ve Akdeniz kıyılarında yeni tür gözlemlerinin oldukça mümkün olduğunu bir kez daha düşündürtmektedir.

Deniz memelilerinde türlere ait sayısal farklılığı ortaya koyan yersel ve zamansal veri setlerinin türlerin biyo-ekolojisinin anlaşılmasında ve korunmasında önemli bir 
DEU FMD 21(61), 279-285, 2019

yeri vardır [23]. Bu durum çalışmasında üretilen bilgi ulusal politikaların yönlendirilmesinde önemli katkı sağlamakla birlikte, çok amaçlı bilgi üretmek adına sınırlı kalmıştır. Gerek geçmiş çalışmalardan elde edilen bilginin kısıtlı olması, gerekse veri setini oluşturan rastlantısal gözlemlerden sınırlı veri elde edilmesi sistemin sınırlarını belirleyen en önemli durumlardır. Bununla birlikte, sistemli yapılacak çalışmaların artması ile üretilen bu bilgi sisteminin gerek yersel gerekse zamansal analizlerde kullanılması imkanlı hale getirilerek, türlere ait anlayıșın arttırılması yanında, daha etkili yönetim ve koruma planlarının oluşturulması mümkün olabilir.

Sonuç olarak, Türkiye denizlerinde gözlemlenmiş setase türlerine ait geçmiş çalışmalar ve rastlantısal gözlemler toplanılarak bir bilgi sistemi durum çalışması gerçekleștirilmiștir. Geliștirilen bilgi sistemi kullanılarak yapılan analizlerle türlere ait coğrafik dağılımı ve coğrafik bilgi boşluklarının tespitine yönelik bilgi ortaya konulmuştur. Bu sayede ulusal olarak türlerin korunmasına yönelik bölgesel ve/veya türe yönelik yönetim planlarının belirlenmesine katkı sağlanmıștır. Çalıșma kapsamında tespit edilen türlerden üçünün $(D$. delphis, $P$. phocoena ve $P$. catadon) "Tehlikede" ve ikisinin de ( $S$. coruleoalba ve $T$. truncatus) "Hassas" olarak IUCN (Uluslararası Doğayı Koruma Birliği) tarafından sınıflandırılmıș olması, türler üzerinde olan anlayıșın arttırılmasının ve daha etkin yönetim kararlarının geliștirilmesinin önemini bir kez daha ön plana getirmektedir.

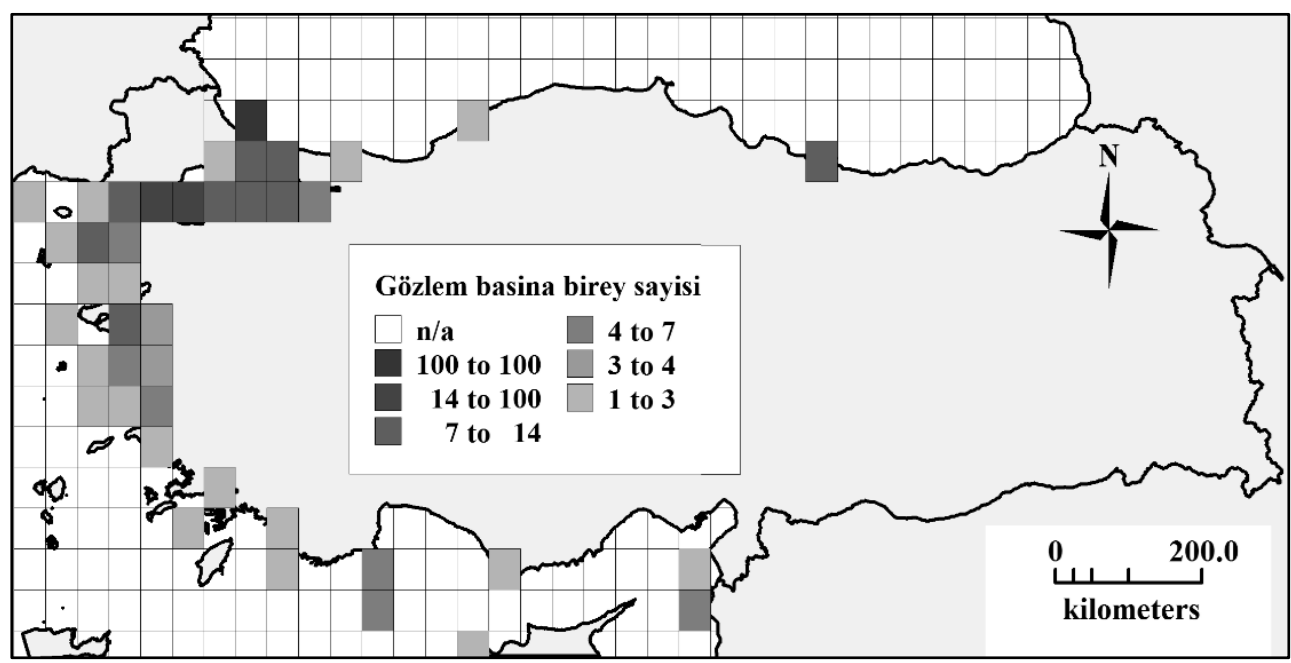

Şekil 1. Tüm türlere ait gözlem başına düşen birey sayısı dağılım 
DEU FMD 21(61), 279-285, 2019

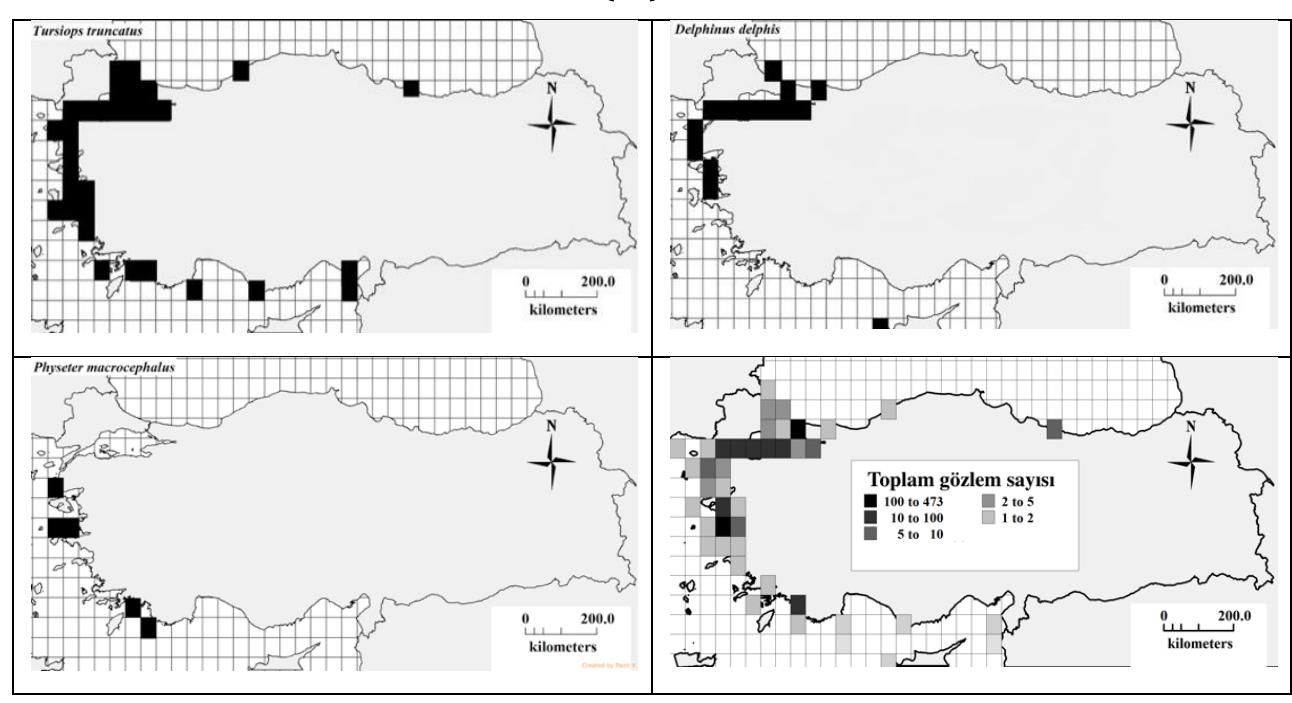

Şekil 2. En geniş yayılım gösteren 2 yunus türü (üst); 1 balina türüne (sol alt) ait gözlem dağılımı ve tüm türlere ait gözlem dağılımı (sağ alt) 


\section{Kaynakça}

[1] Notarbartolo di Sciara G. 2002. Cetacean species occurring in the Mediterranean and Black Seas. G. Notarbartolo di Sciara (Ed.), Cetaceans of the Mediterranean and Black Seas: state of knowledge and conservation strategies. A report to the ACCOBAMS Secretariat, Monaco, February 2002. Bölüm 3, s. 17

[2] Notarbartolo di Sciara G., Birkun A. Jr. 2010 Conserving whales, dolphins and porpoises in the Mediterranean and Black Seas: an ACCOBAMS status report, 2010. ACCOBAMS, Monaco. $212 \mathrm{~s}$

[3] Güçlüsoy H. 2006. Türkiye'nin Orta Ege kıyılarında deniz memelilerinin durumu ve balıkçlıkla etkileşimi. Dokuz Eylül Üniversitesi, Fen Bilimleri Enstitüsü, Doktora Tezi, 116s, İzmir.

[4] Öztürk B. 1996. Balinalar ve Yunuslar. Anahtar yayınevi, Istanbul, 119s.

[5] Alan V., Bengil F., Kaboğlu G., Güçlüsoy H. 2017. The First Photo-Identification Study on Bottlenose Dolphins (Tursiops truncatus) in the Foça Special Environmental Protection Area, Turkey. Aquatic Mammals, Cilt 43(3), s. 302-307, DOI 10.1578/AM.43.3.2017.302

[6] Tonay A. M., Dede, A., Öztürk A. A. 2008. Cetacean strandings in the Turkish western Black Sea coast during spring months in 2003-2005. Proc. 22nd Annual Conf. European Cetacean Society, Egmond aan Zee, the Netherlands.

[7] Sönmez R., Kankus J., Bengil F., Güçlüsoy H. 2011. Can Press Provide Some Insight on the Cetacean Strandings on the Turkish Coasts? 25th Conference of the European Cetacean Society, 21st - 23rd March 2011, Spain

[8] Öztürk B., Öztürk A. A., Dede A. 2001. Dolphin bycatch in the swordfish driftnet fishery in the Aegean Sea. Rapp. Comm. int. Mer Médit.,Cilt 36: s. 308.

[9] Enül E. 2009. Deniz Memelileri Bilimi ve Yönteminin Türkiye'deki Durumu ve Deniz Memelilerinin Ege'deki Trol Balıkçılığı ile Etkileșimi. Dokuz Eylül Üniversitesi, Fen Bilimleri Enstitüsü. Yüksek Lisans Tezi, 67s, İzmir.

[10] Kinzelbach R. 1991. Records of the Bottlenosed Dolphin, Tursiops truncatus, in the Aegean Sea and the Sea of Marmara (Cetacea: Delphinidae): Zoology in the Middle East, Cilt 5(1), s. 5-10. DOI 10.1080/09397140.1991.10637597

[11] Dede A. 2000. Türk Boğazlar Sisteminde Yaşayan Deniz Memelileri populasyonları üzerine araștırmalar. İstanbul Üniversitesi, Dokuz Eylül Üniversitesi, Fen Bilimleri Enstitüsü. Doktora Tezi, $62 \mathrm{~s}$, İstanbul.

[12] Dede A. Öztürk A.A., Tonay A. M. 2008, Cetacean Surveys in the Istanbul (Bosphorus) Strait in 2006 Proc. 22nd Annual Conf. European Cetacean Society, Egmond aan Zee, the Netherlands.

[13] Dede A., Saad A., Fakhri M. ve Öztürk A.A. 2012 Cetacean sightings in the Eastern Mediterranean Sea during the cruise in summer 2008. J. Black
Sea/Mediterranean Environment Cilt 18, No. 1, s 49-57.

[14] Güçlüsoy H., Veryeri N., Cirik S. 2005. The Status of Cetaceans in the İzmir Bay: Preliminary Results. MEDCOAST, The seventh International Conference on the Mediterranean Coastal Areas, 2005, Cilt I, Management of Living Sources, Özet Kitabı, Kuşadası-Turkey.

[15] Okuș E., Yüksek A. 2006. Gökova Özel Çevre Koruma Bölgesinin Kıyı ve Deniz Alanlarının Biyolojik Çeşitliliğinin Tespiti. Proje Raporu, Istanbul Universitesi, Deniz Bilimleri ve İșletmeciliği Enstitüsü

[16] Öztürk B., Dede A., Tonay A. M., Öztürk A. A. 2009. Cetacean sightings in the Aegean Sea in summer 2007 and 2008. Proc. 23rd Annual Conf. European Cetacean Society, Istanbul, Turkey.

[17] Öztürk B., Öztürk A. A., Dede A. 1999. Cetacean bycatch in the western coast of the Turkish Black Sea in 1993-1997. 13. Annual Conference of the European Cetacean Society. Valencia, Spain.

[18] Tonay A. M., Dede A., Öztürk A. A., Öztürk B. 2009. Cetacean strandings in the Turkish Straits System (TSS) and the Northern Aegean Sea coast of Turkey during 1999-2008. Proc. 23rd Annual Conf. European Cetacean Society, Istanbul, Turkey.

[19] TUDAV, 2010. Kașalot Balinasının Kurtarılması. http://www.tudav.org/index.php?option=com_con tent\&view=article\&id=80\%3Akaalot-balinasnnkurtarlmas\&catid $=36 \% 3$ Abalina-ve-yunusaratrmalar\&Itemid=50\&lang=tr (Erişim Tarihi: 14 09 2014)

[20] Jefferson, T.A., Leatherwood, S., Webber M. A. 1993. FAO species identification guide. Marine mammals of the world. s. 320, Roma, FAO.

[21] Taylor B.L., Baird R., Barlow J., Dawson S.M., Ford J., Mead J.G., Notarbartolo di Sciara G., Wade P., Pitman R.L. 2008. Mesoplodon densirostris. The IUCN Red List of Threatened Species 2008: e. T13244A3426474.

[22] Taylor B.L., Baird R., Barlow J., Dawson S.M., Ford J., Mead J.G., Notarbartolo di Sciara G., Wade P., Pitman R.L. 2008. Mesoplodon europaeus. The IUCN Red List of Threatened Species 2008: e. T13245A3427527.

[23] Magera A. M., Mills Flemming J. E., Kaschner K., Christensen L. B., Lotze H. K. 2013. Recovery Trends in Marine Mammal Populations. PLoS ONE, Cilt 8(10),

e77908. 